\title{
"Apology Accepted": A Cross-Cultural Study of Responses to Apologies by Native Speakers of English and Chinese
}

\author{
Jue $\mathrm{Wu}^{1} \&$ Wei Wang ${ }^{2}$ \\ ${ }^{1}$ School of Foreign Language Studies, Changshu Institute of Technology, Jiangsu, China \\ ${ }^{2}$ College of Foreign Languages and Literatures, Fudan University, Shanghai, China \\ Correspondence: Jue Wu, School of Foreign Language Studies, Changshu Institute of Technology, Jiangsu, China. \\ E-mail: likejackie@163.com
}

Received: January 23, 2016 Accepted: February 12, 2016 Online Published: March 28, 2016

doi:10.5539/ijel.v6n2p63

URL: http://dx.doi.org/10.5539/ijel.v6n2p63

\begin{abstract}
This study focuses on the strategies of responding to apologies from a cross-cultural perspective. It analyzes and compares apology response (AR) strategies adopted by three groups of English native speakers (ENS), Chinese native speakers (ENS) and Chinese EFL learners for potential cross-cultural differences. Results indicate that all three groups most favor the strategy of Indirect Acceptance to show politeness when responding to apologies. Given contextual factors such as social power, social distance and severity of offence, the three groups display different patterns of AR strategies. Chinese EFL learners' AR strategies are similar to those of Chinese native speakers, indicating the influence of native culture on their pragmatic competence.
\end{abstract}

Keywords: apology responses, strategies, cross-cultural comparison, Chinese EFL learners

\section{Introduction}

The current literature has focused on researching the speech act of apology in different cultural contexts as well as non-native speakers' pragmatic competence of making apologies in a target language (Al-Zumor, 2011; Bataineh \& Bataineh, 2008; Bergman \& Kasper, 1993; Cheng, 2011; Cohen \& Shively, 2007; Garc1'a, 1989; House, 1988; Linnell, 1992; Kondo, 1997; Olshtain, 1983; Sabate \& Curell, 2007; Shardakova, 2005; Sugimoto, 1997; Trosborg, 1987; Xiang, 2004). However, there have been few studies on responses to apologies, and differences in apology responses by speakers from different cultures have been overlooked as well. Bataineh \& Bataineh (2008) point out that the victim's potential reaction to the wrongdoer's apology is an underdeveloped area, which is in need of further explorations.

Influenced by cultures and customs, people coming from various cultural backgrounds may respond to apologies in different ways. Wierzbicka (1991) has indicated that "different cultures find expression in different systems of speech acts, and that different speech acts become entrenched, and, to some extent, codified in different languages" (p. 26). People from Western countries tend to be more direct in verbal communication than those from Eastern countries (Gu, 1992). The current study, therefore, is going to explore the potential differences in responding to apologies between English native speakers (ENS) and Chinese native speakers (CNS), as well as Chinese EFL learners' responses to apologies in English. It aims to answer the following two questions:

1) What are the strategies of responding to apologies used by ENS and CNS as well as Chinese EFL learners respectively?

2) To what extent can the social power and distance between speakers and the severity of offence influence the responses to apologies by ENS and CNS as well as Chinese EFL learners?

\section{Literature Review}

Bataineh \& Bataineh $(2008$, p. 793) argued that "apology is the speech act through which the wrongdoer acknowledges responsibility and seeks forgiveness for what he/she has done." This speech act involves two parties-the wrongdoer/the apologizer and the victim/the apology respondent. The wrongdoer has committed the act which has harmed the victim, and is supposed to apologize for what he/she has done. The victim is the person who was harmed, whether psychologically, physically, or materially, by the act warranting apology.

Apology is regarded as one of the remedial devices to reestablish social harmony among interactants (Goffman, 
1971), and a face-threatening act (FTA) (Brown \& Levinson, 1987), which "pays attention to the addressee's negative face" (Coates \& Cameron, 1988, p. 30). For an apology to be convincing, the offender has to use one or more strategies, such as explanations, acknowledgement of responsibility, and promise of forbearance (Holmes, 1990). Previous studies on apology strategies have shown that the apologizer apply many different kinds of apology strategies to save the victim's face (Fraser, 1981; Olshtain \& Cohen, 1983; Sugimoto, 1997; Trosborg, 1987).

According to Brown \& Levinson's Politeness Theory (1987), apology is an FTA that cares about the addressee's negative face. An FTA is often influenced by three contextual factors - social power, social distance and the imposition of acts. When making apologies, speakers will choose different expressions under the influences of these factors (Chen, 2013). For example, if the apologizer has the same social status with the apology receiver, he/she may say, "Sorry babe, I'm late." If the apologizer's social status is lower than that of the apology receiver, he/she may say, "Professor Smith, I'm terribly sorry for being late!" The social distance between the apologizer and the apology receiver also plays an important role in making apologies. For instance, an apology made between two close friends may be "Oops! Sorry buddy." While facing a total stranger, one may say "I'm so sorry for that. It's my fault. Please forgive me, Ma'am!" Finally, the severity of offence also influences the choice of apology strategies. For example, if the offence is severe, one may make a formal apology: "I'm really sorry that I lost your bike. I didn't mean to do that! I'll buy you a new one." If the offence is relatively light, one may just say "Sorry. Are you OK?"

The above examples and findings in Chen's study (2013) indicate that the speech act of apology is influenced by three contextual factors-social power, social distance and the imposition of acts (or severity of offence in apologies). Like apologizing, responding to apologies is also an FTA that concerns the addressee's positive face. The three contextual factors, consequently, may also influence this speech act. Therefore, the current study, with a focus on the influence of the three factors, investigates the speech act of apology responses by ENS, CNS and Chinese EFL learners.

Although apology strategies across different cultures have been well studied, little is known about the apology response strategies either within one culture or in cross-cultural contexts. Only a few studies have investigated apology responses by native Chinese speakers (Fu, 2010; Fu, Jiang \& Liao, 2012; Qian \& Yang, 2005). Qian \& Yang (2005) conducted a survey among 84 Chinese undergraduates. Taking into consideration the four contextual factors of social distance, social power, severity of offence, and obligation to apologize (their own term), they designed seven scenarios which involved the speech act of responding to apologies. Based on the data collected from the questionnaires, they categorized five apology responses by native Chinese speakers: illocutionary force indicating device (IFID), cautions, comforting the hearer, explaining things away, and conditional forgiveness. Based on Owen's apology remedial model (1983), Fu et al. (2012) found three first-level strategies of responding to apologies-formulaic responses, extended responses, and withholding-in the communication between English and Chinese interlocutors. There were several secondary strategies under each first-level strategy. For example, there were three secondary strategies of withholding: complaining, asking for explanations, and making requests.

However, the current classification of apology response strategies in Chinese is not thorough and specific enough to reflect the features of Chinese apology responses as well as the differences between ENS and CNS in responding to apologies. Aiming to make a further exploration in this area, we will reclassify the strategies of responding to apologies in both English and Chinese. And based on the new classification, we will investigate Chinese EFL learners' pragmatic competence in terms of apology responses in English.

\section{The Current Study}

\subsection{Participants}

Three groups of participants took part in the current study (see Table 1). The 32 participants of ENS group were university students from a university in the western part of the United States. Their age range was from 21 to 27. The participants in CNS group and Chinese EFL learners group were sophomores from a local university in the southern part of Jiangsu Province, China, and the age range for both groups was from 19 to 21 . The 32 students in CNS group majored in Chinese literature. They all speak Mandarin Chinese and have all passed the National Mandarin Chinese Level Test. The students in EFL group were 32 English majors with an average English learning history of 7.6 years (ranging from 7 to 9 years). These EFL learners were all born in China, and none of them had ever been to an English-speaking country. All of them learned English from schools in China, and they have all passed the TEM-4 (Test for English Majors, Band 4) in college. 
Table 1. Participants

\begin{tabular}{llll}
\hline Speaker groups & ENS Group, $(\mathbf{n}=\mathbf{3 2})$ & CNS Group, $(\mathbf{n}=\mathbf{3 2})$ & EFL Group, $(\mathbf{n}=\mathbf{3 2})$ \\
\hline Number of males & 17 & 14 & 10 \\
Number of females & 15 & 18 & 22 \\
Age in years, mean & 23.2 & 20.3 & 20.6 \\
Language proficiency & English native speakers & Chinese native speakers & Chinese EFL learners \\
\hline
\end{tabular}

\subsection{Instrument}

The main data sources of speech act performance are naturally-occurring speech, elicited data via discourse completion tests (DCTs) and role-plays (Economidou-Kogetsidis, 2013). Naturally-occurring speech is considered to be ideal, but difficult to be collected. Besides, researchers have little control over speakers' production, thus no guarantee that the speech act under investigation occurs at all or that enough tokens will be produced (Kasper \& Dahl, 1991).

DCTs, both written and oral, have been widely used to gather and compare speech acts data ever since the creation/institution of the cross-cultural speech act realization projects (CCSARP) (Blum-Kulka, 1982; Blum-Kulka et al., 1989). However, the DCT, especially WDCT (written discourse completion test), has been widely and severely criticised due to its obvious weakness (Economidou-Kogetsidis, 2013; Hassall, 1999; Kasper, 2000; Yi, 2001; etc.). It has been found that DCT responses are shorter, simpler, less face-attentive and negotiatory, and less emotionally involved than the responses in naturally-occurring speech (Beebe \& Cummings, 1996; Bodman \& Eisenstein, 1988; Hartford \& Bardovi-Harlig, 1992; Turnbull, 1997). These studies point out that the authenticity of the situations is limited; the hypothetical nature of the situations in DCT simplifies the complexity of interactions in real conversation. In addition, DCT cannot bring out the extended negotiation which commonly occurs in authentic discourse due to the absence of an interlocutor.

A number of studies have compared DCTs and role-plays. By studying the expression of thanking and responding to thanks by native and non-native speakers of English, Eisenstein \& Bodman (1993) found that the role-plays went beyond the WDCT data by providing additional insights into the functions as they existed in a conversational interaction. Margalef-Boada (1993) examined the speech act of refusals by native speakers of German, Spanish, and German learners of Spanish, and the results showed that the role-plays provided longer, richer and more complex refusals. Felix-Brasdefer (2003), who investigated refusal strategies among native and non-native speakers of English and Spanish, found that the role-play data displayed higher levels of mitigation, elaboration and a wider range of indirect strategies.

Role-plays are believed to be relatively easy in implementation and can well maintain researcher control; they can reveal speakers' pragmatic performance in near-authentic settings; and can reflect the influence of such factors as the social power and distance between speakers in multiple turns (Economidou-Kogetsidis, 2012; Felix-Brasdefer, 2007; Otcu \& Zeyrek, 2008; Woodfield, 2012). Given these advantages, the current study uses role-plays to collect apology responses.

\subsection{Procedure}

We designed 8 situations in which one interlocutor has done something harmful to the other interlocutor and is supposed to make apologies to the victim. A general description of the apology-provoking scenarios is shown in Table 2 .

Table 2. The 8 apology-provoking scenarios

\begin{tabular}{|c|c|c|c|}
\hline Description of the scenarios & Power & Distance & Severity \\
\hline $\begin{array}{l}\text { 1. The professor is twenty minutes late for the appointment with the student, who has arrived } \\
\text { on time, and is supposed to apologize to the student. }\end{array}$ & $-P$ & $=\mathrm{D}$ & $-\mathrm{O}$ \\
\hline $\begin{array}{l}\text { 2. The professor has lost the student's graduation thesis, which is the only copy of the } \\
\text { student, and is supposed to apologize to the student. }\end{array}$ & $-\mathrm{P}$ & $=\mathrm{D}$ & $+\mathrm{O}$ \\
\hline $\begin{array}{l}\text { 3. The student leaves the right paper at home and turns in the wrong paper to the professor, } \\
\text { and is supposed to apologize to the professor. }\end{array}$ & $+\mathrm{P}$ & $=\mathrm{D}$ & $-\mathrm{O}$ \\
\hline $\begin{array}{l}\text { 4. The student has lost one of the professor's important files, and is supposed to apologize to } \\
\text { the professor. }\end{array}$ & $+\mathrm{P}$ & $=\mathrm{D}$ & $+\mathrm{O}$ \\
\hline $\begin{array}{l}\text { 5. The boy is twenty minutes late for the date with his girlfriend, and is supposed to } \\
\text { apologize to her. }\end{array}$ & $=\mathrm{P}$ & $-\mathrm{D}$ & $-\mathrm{O}$ \\
\hline $\begin{array}{l}\text { 6. The girl has accidentally broken one of her boyfriend's favorite cups with a signature of a } \\
\text { football star on it, and is supposed to apologize to him. }\end{array}$ & $=\mathrm{P}$ & $-\mathrm{D}$ & $+\mathrm{O}$ \\
\hline
\end{tabular}




$\begin{aligned} & \text { 7. The boy accidentally steps on the girl's foot on a bus, and is supposed to apologize to the } \\ & \text { girl, who he does not know. }\end{aligned} \quad+\mathrm{P}$
8. The girl accidentally splashes a glass of water over the boy's computer, leading to its
collapse, and is supposed to apologize to the boy, who she does not know.

These situations had been confirmed by two professors from American and Chinese universities (the interrater reliability $=.86$ ) as valid and very close to authentic settings. These 8 situations took into consideration three independent variables: social power, social distance of the interlocutors, and the severity of the offence. The variable "social power", which reflects the power of the apology receiver relative to the apologizer, was assigned a conventional three-level division: high $(+\mathrm{P})$, equal $(=\mathrm{P})$ and low $(-\mathrm{P})$. "Social distance", which refers to the degree of familiarity between the apologizer and the victim, was divided into three levels: intimate (-D), acquaintance $(=\mathrm{D})$ and stranger $(+\mathrm{D})$. "Severity of offence" was considered at two levels: severe $(+\mathrm{O})$ and not severe (-O).

In the first four scenarios, some of the participants were asked to play the role of a professor, a role that they might not have played before. It is not good to have participants play such unfamiliar roles because they might merely guess what they might say in those given situations (Hudson, Detmer, \& Brown, 1995). This is a limitation of the current study. However, we designed these situations mainly because the variable "social power" between the interlocutors in these cases $(+\mathrm{P})$ is different from that in the scenarios 5 to $8(=\mathrm{P})$. Besides, the participants themselves might not have acted as professors, but they had close contact with their professors in their daily life, thus being quite familiar with what professors would do and say. Our pilot test proved that to be workable.

A pilot test was conducted before primary data collection. We asked 4 ENSs, 4 CNSs, and 4 Chinese EFL learners from a university in Jiangsu Province in China to role-play conversations according to the 8 scenarios. These conversations were relatively long and detailed enough to elicit apology response strategies. We asked the two raters (two professors from American and Chinese universities) to examine the participants' performance in the first four scenarios, and they both noticed that the students' role-playing of professors was "quite acceptable".

After the pilot test, we conducted the investigation on a larger scale. We collected the data at the local Chinese university, and asked a friend studying in the American university to collect data from the ENSs. For each of the three targeted speaker groups, 16 pairs were asked to play roles according to the 8 apology-provoking scenarios. Each pair was asked to make one conversation based on one scenario they were assigned to, and each scenario was role-played by two pairs, so we had 16 total role-plays for our data analysis. The participants in each pair were asked to read the role-play instruction before they carried out the conversation, and then they were asked to work together to make a dialogue according to the roles they were supposed to play in the scenario. For each pair, one participant played the role of the apologizer, and the other played the role of the apology respondent. Participants from ENS Group and EFL Group read the instruction in English and were asked to role-play conversations in English, and participants from CNS Group carried out dialogues in Chinese according to the instruction in Chinese. All the conversations were tape-recorded and then transcribed.

\subsection{Data Analysis}

Based on the data collected from the three targeted speaker groups, we identified different patterns of apology responses (ARs) from the role-play transcripts. Owen's (1983) and Fu's (2012) categories of apology responses were used as an initial coding model, and were further developed to adapt to the current data, as seen in the following example of scenario 7 .

(1) Scenario 7: On a very crowded bus, a boy accidentally steps on a girl's foot because the bus driver makes an abrupt stop. The boy and the girl don't know each other. Now, the boy needs to apologize to the girl, and the girl needs to respond to the boy's apology.

Boy: I am so sorry!

Girl: (1) That's okay. (2) It's not your fault.

Boy: Are you OK?

Girl: (3) No problem.

Boy: Bus is crowded.

Girl: (4) I know it is rush hour. 
In this conversation, the girl used four strategies to respond to the boy's apologies. "(1) That's okay" is a formulaic response of Direct Acceptance. "(2) It's not your fault" is a strategy of downgrading. "(3) No problem" is minimization and "(4) I know it is rush hour" is a strategy of accepting the apologizer's explanation. "Downgrading", "minimization" and "accepting explanation" can be labeled as Indirect Acceptance.

In this way, we classified the strategies of ARs into 4 macro strategies: Direct Acceptance (DA), Indirect Acceptance (IA), Direct Refusal (DR) and Indirect Refusal (IR), as well as 23 micro strategies (see Table 3).

Table 3. The adapted strategy framework of Apology Responses (ARs)

\begin{tabular}{|c|c|c|c|}
\hline $\begin{array}{l}\text { Macro-level } \\
\text { ARs }\end{array}$ & $\begin{array}{l}\text { Micro-level } \\
\text { ARs }\end{array}$ & Examples in English & Examples in Chinese* \\
\hline $\begin{array}{l}\text { Direct } \\
\text { Acceptance }\end{array}$ & Formulaic responses & $\begin{array}{l}\text { "Apology accepted." } \\
\text { "I accept your apology." } \\
\text { "It's OK." } \\
\text { "It's OK, really!" } \\
\text { "Oh, it's OK." } \\
\text { "It's OK. It's OK." }\end{array}$ & $\begin{array}{l}\text { “我接受你的道歉。” } \\
\text { “没关系。” } \\
\text { “不要紧。” } \\
\text { “真的不要紧。” } \\
\text { “啊呀, 没关系啦! ” } \\
\text { “没关系, 没关系。” } \\
\text { 严。 }\end{array}$ \\
\hline $\begin{array}{l}\text { Indirect } \\
\text { Acceptance }\end{array}$ & $\begin{array}{l}\text { Providing solutions } \\
\text { Accepting promises }\end{array}$ & $\begin{array}{l}\text { "Go home and bring the file." } \\
\text { A: "I promise I will never be late } \\
\text { again!" } \\
\text { B: "OK, I believe you." }\end{array}$ & $\begin{array}{l}\text { “马上回去拿。” } \\
\text { 甲: “我保证, 下不为例! ” } \\
\text { 乙: “好吧, 这次就相信你一回。” }\end{array}$ \\
\hline & $\begin{array}{l}\text { Accepting remedies } \\
\text { Downgrading } \\
\text { Minimizations } \\
\text { Blaming oneself } \\
\text { Appreciation } \\
\text { Expressing concerns } \\
\text { Shifts of topic } \\
\text { Shifts of blame }\end{array}$ & $\begin{array}{l}\text { A: "The bus is so crowded!" } \\
\text { B: "Yes, it is." } \\
\text { A: "I'll make it up for you." } \\
\text { B: "That sounds good." } \\
\text { "It doesn't matter. It's not your fault." } \\
\text { "It's nothing. It's just a cup." } \\
\text { "I was in a bad mood, too." } \\
\text { "Thank you." } \\
\text { "Are you hungry?" } \\
\text { "Forget it. Let's eat!" } \\
\text { "The bus driver must be crazy!" }\end{array}$ & $\begin{array}{l}\text { 甲: “路上堵车了。” } \\
\text { 乙: “嗯, 这个时间正是下班高峰。” } \\
\text { 甲: “对不起! 我马上回去拿报告。” } \\
\text { 乙: “好吧, 尽快拿过来。” } \\
\text { “没事, 那不怪你。” } \\
\text { “没事, 一点儿都不疼。” } \\
\text { “这事我也有不对的地方。” } \\
\text { “谢谢你!” } \\
\text { “学习太累了吧?” } \\
\text { “不说了。我们出去走走吧。” } \\
\text { “这司机, 车也开得太猛了。” }\end{array}$ \\
\hline $\begin{array}{l}\text { Direct } \\
\text { Refusal } \\
\text { Indirect } \\
\text { Refusal }\end{array}$ & $\begin{array}{l}\text { Formulaic responses } \\
\text { Intensifiers } \\
\text { Descriptions } \\
\text { Expressing strong } \\
\text { emotions } \\
\text { Refusing remedies }\end{array}$ & $\begin{array}{l}\text { "I don't accept your apology." } \\
\text { "Apology not accepted, really." } \\
\text { "You step on my foot!" } \\
\text { "It's my favorite cup!" } \\
\text { "I hate you!" } \\
\text { A: "I'll buy you another one!" } \\
\text { B: "No way! I just want the original } \\
\text { one!" }\end{array}$ & $\begin{array}{l}\text { “我不接受你的道歉。” } \\
\text { “道歉没用, 真的。” } \\
\text { “你踩到我啦! ” } \\
\text { “那是我最喜欢的啊！” } \\
\text { “别让我再见到你!” } \\
\text { 甲: “我再给你买一个新的吧? ” } \\
\text { 乙: “不要！我就要原来那个! ” }\end{array}$ \\
\hline & $\begin{array}{l}\text { Blaming \& } \\
\text { Complaining } \\
\text { Cautions } \\
\text { Threatening }\end{array}$ & $\begin{array}{l}\text { "You are so careless!" } \\
\text { "Bad luck!" } \\
\text { "Be more careful next time!" } \\
\text { "Bring it to me tomorrow, or you'll be } \\
\text { failed!" }\end{array}$ & $\begin{array}{l}\text { “你怎么那么不小心啊? ” } \\
\text { “算我倒電。” } \\
\text { “以后仔细点! ” } \\
\text { “下次再迟到, 别怪我不客气! ” }\end{array}$ \\
\hline & Asking for reasons & $\begin{array}{l}\text { "Why are you late again? What } \\
\text { happened?" } \\
\text { "What are you going to do about my } \\
\text { computer?" }\end{array}$ & $\begin{array}{l}\text { “怎么又迟到了? 出什么事了? ” } \\
\text { “今天是截止日期, 你打算怎么办? ” }\end{array}$ \\
\hline
\end{tabular}

Note. All the examples are taken from the data of the current study. The examples in Chinese are not just the translated versions of the examples in English. They stand alone as examples of apology responses in Chinese.

\section{Results and Discussion}

\subsection{A General Pattern of Macro-Level ARs}

Based on the above mentioned categorization of AR strategies, we identified 452 times of the use of apology response strategies by the three groups. Of these 452 uses, 157 were from the group of ENS, 148 were produced 
by CNS, and the Chinese EFL learners produced 147 strategies in responding to apologies. Table 4 and Figure 1 display a detailed description of the distribution of the four macro-level strategies of ARs.

Table 4. Macro-level strategies of ARs by three groups

\begin{tabular}{lllllll}
\hline Macro-level strategies & $\begin{array}{l}\text { Groups } \\
\text { ENS }\end{array}$ & & CNS & & EFL & \\
& Number & Percentage & Number & Percentage & Number & Percentage \\
\hline Direct Acceptance & 28 & $17.83 \%$ & 30 & $20.27 \%$ & 28 & $19.05 \%$ \\
Indirect Acceptance & 73 & $46.50 \%$ & 60 & $40.54 \%$ & 71 & $48.30 \%$ \\
Direct Refusal & 0 & 0 & 1 & $0.68 \%$ & 0 & 0 \\
Indirect Refusal & 56 & $35.67 \%$ & 57 & $38.51 \%$ & 48 & $32.65 \%$ \\
Total & $\mathbf{1 5 7}$ & $\mathbf{1 0 0 \%}$ & $\mathbf{1 4 8}$ & $\mathbf{1 0 0 \%}$ & $\mathbf{1 4 7}$ & $\mathbf{1 0 0 \%}$ \\
\hline
\end{tabular}

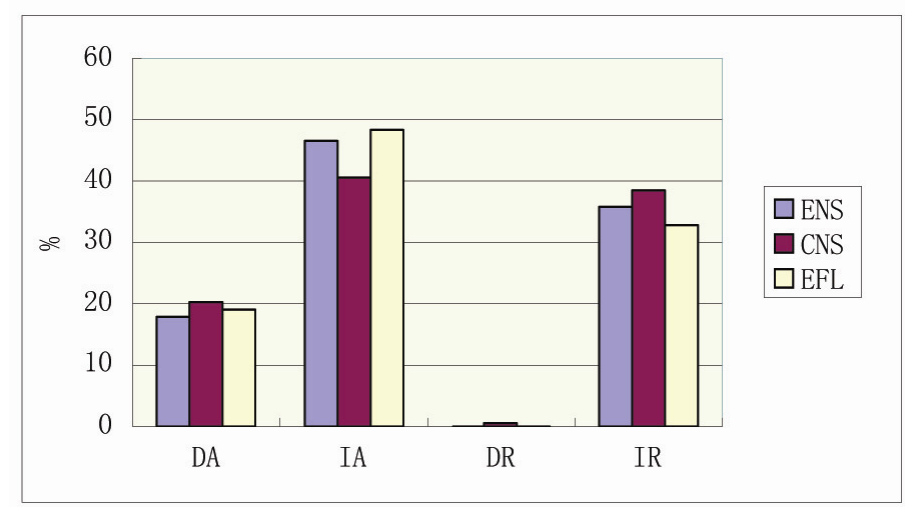

Figure 1. Macro-level strategies of ARs by three groups

Table 4 and Figure 1 show a general pattern of apology responses made by the three speaker groups. $64.33 \%$ of the AR strategies made by the ENSs were acceptance, both direct and indirect; the CNSs also favored the strategy of acceptance with a percentage of $60.81 \%$; the Chinese EFL learners displayed a similar trend with the strategy of acceptance taking up $67.35 \%$. Acceptance, especially Indirect Acceptance, was the most preferred response by all the three groups, and was used more frequently by EFL Group, followed by ENS Group and CNS Group.

In terms of the strategy of acceptance, the three speaker groups displayed a similar trend, that is, the strategy of Indirect Acceptance was much more widely used than that of Direct Acceptance. However, the disparity between Direct Acceptance strategies and Indirect Acceptance strategies used by CNSs was smaller than that among ENSs and Chinese EFL learners. It suggests that the CNSs were more direct in accepting others' apologies than the ENSs and the Chinese EFL learners, who may be influenced by Western culture after years' of English learning.

Regarding the strategy of refusal, the three groups of participants showed an almost identical tendency: they used much more Indirect Refusal strategies than Direct Refusal strategies. No Direct Refusal strategy was found in the data collected from ENS Group and EFL Group, and only one strategy of Direct Refusal was found in CNS Group. This might indicate that the participants from both western and eastern cultures would take into consideration the face of the addressees and try their best to mitigate the face-threatening act of refusal.

\subsection{The Effect of Social Power on AR Strategies}

An FTA (face-threatening act) is influenced by social power, social distance and the imposition of acts (Brown \& Levinson, 1987). In the speech acts of apology and responding to apologies, the imposition of acts refers specifically to the severity of the offence. All three factors influence the interlocutors' utilization of apology response strategies. In this section and the following two sections, strategies of apology responses in terms of the three factors are analyzed.

For the convenience of comparison, Scenario 1 and Scenario 3 are chosen to examine the influence of social power on the AR strategies. In these two scenarios, the social distance and severity of offence are the same, 
while the social power between the interlocutors is different. In Scenario 1, the social power of the apology receiver is relatively lower than that of the apologizer; and in Scenario 3, we can see the reverse situation. The results of the comparison among the three groups are shown in Table 5 and Figure 2.

Table 5. The effect of social power on AR strategies used by three groups

\begin{tabular}{|c|c|c|c|c|c|c|c|c|c|c|c|c|}
\hline \multirow{3}{*}{$\begin{array}{l}\text { Macro-level } \\
\text { AR strategies } \\
\text { DA }\end{array}$} & \multicolumn{4}{|c|}{ ENS } & \multicolumn{4}{|c|}{ CNS } & \multicolumn{4}{|c|}{ EFL } \\
\hline & \multicolumn{2}{|c|}{ S 1 (-P) } & \multicolumn{2}{|c|}{$\mathrm{S} 3(+\mathrm{P})$} & \multicolumn{2}{|c|}{$\mathrm{S} 1(-\mathrm{P})$} & \multicolumn{2}{|c|}{$\mathrm{S} 3(+\mathrm{P})$} & \multicolumn{2}{|c|}{ S $1(-P)$} & \multicolumn{2}{|c|}{$\mathrm{S} 3(+\mathrm{P})$} \\
\hline & 2 & $15.38 \%$ & 3 & $13.64 \%$ & 6 & $18.75 \%$ & 5 & $22.73 \%$ & 4 & $14.81 \%$ & 5 & $16.67 \%$ \\
\hline IA & 7 & $53.85 \%$ & 10 & $45.45 \%$ & 18 & $56.25 \%$ & 9 & $40.91 \%$ & 14 & $51.85 \%$ & 17 & $56.67 \%$ \\
\hline DR & 0 & 0 & 0 & 0 & 0 & 0 & 0 & 0 & 0 & 0 & 0 & 0 \\
\hline IR & 4 & $30.77 \%$ & 9 & $40.91 \%$ & 8 & $25.00 \%$ & 8 & $36.36 \%$ & 9 & $33.34 \%$ & 8 & $26.66 \%$ \\
\hline Total & 13 & $100 \%$ & 22 & $100 \%$ & 32 & $100 \%$ & 22 & $100 \%$ & 27 & $100 \%$ & 30 & $100 \%$ \\
\hline
\end{tabular}
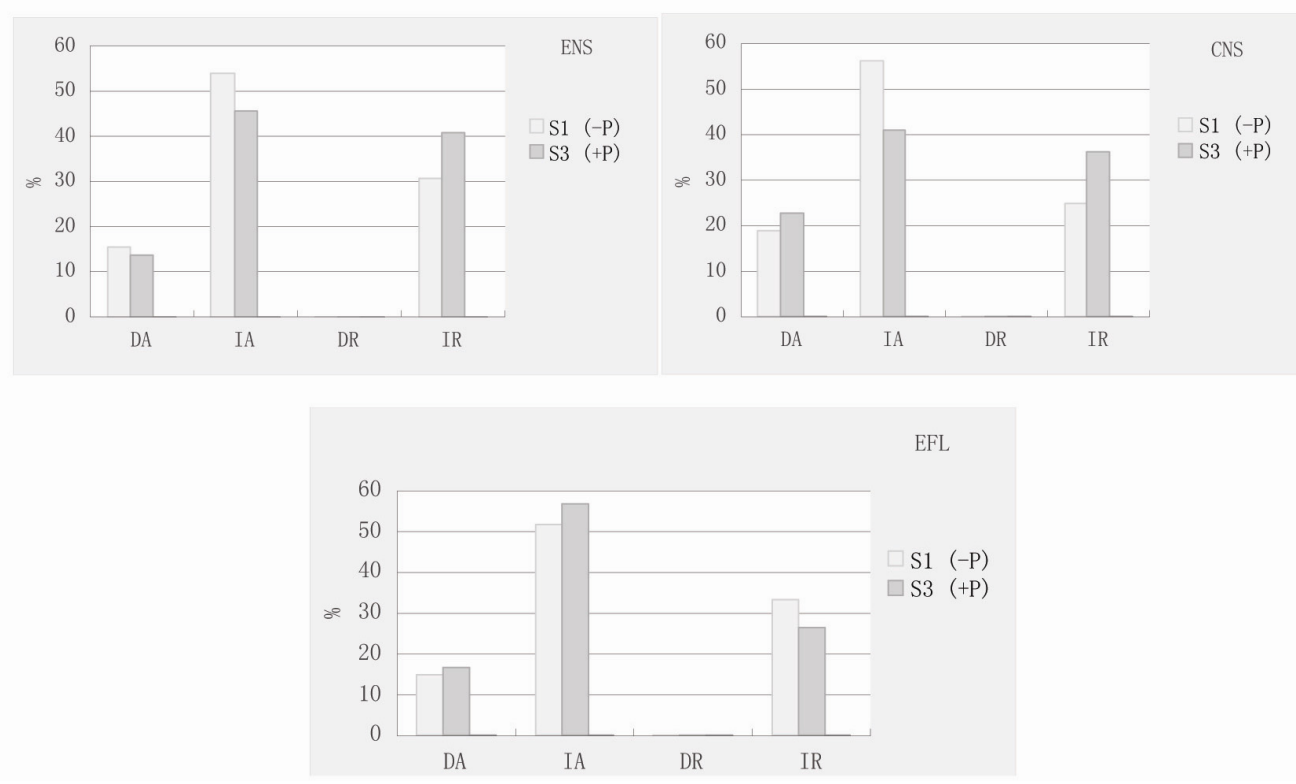

Figure 2. The effect of social power on AR strategies used by three groups

The above table and figure suggest that social power plays an important role in participants' responses to apologies, including both the ENSs and CNSs. When the social power of the apology receiver is lower than that of the apologizer, ENSs tend to use the strategies of Indirect Acceptance (53.85\%) more often than those of Direct Acceptance (15.38\%) and Indirect Refusal (30.77\%). While in the reverse situation, Indirect Acceptance $(45.45 \%)$ and Indirect Refusal $(40.91 \%)$ are preferred. When the social power of the apology receiver is higher than that of the apologizer, there is an increase in Indirect Refusal strategies and a decrease in Indirect Acceptance.

This indicates that for ENSs, when facing apologizers of higher social status, the apology receivers with lower social status will respond to the apologies by using more polite strategies, that is, the macro-level strategy of Indirect Acceptance, among which the micro-level AR strategies of "downgrading" and "accepting explanation" are the most frequently used ones. For example, in Scenario 1, the professor apologizes to his student for being late for the appointment:

(2) Professor: Sorry I'm late. I got caught up at a meeting, and the traffic was terrible.

Student: It's okay, I haven't been here too long. Traffic can be pretty bad this time of day.

In this example, the student takes into consideration the professor's face, and uses the strategies of "downgrading" ("I haven't been here too long") and "accepting explanation" ("Traffic can be pretty bad this time 
of day") in order to save the professor's positive face.

In the reverse situation, the apologizer's social status is lower than that of the respondent. In Scenario 3, the student has to apologize to her professor for turning in the wrong paper:

(3) Student: Professor Smith, I am sorry-I accidentally brought the wrong paper. I left the right one at home. Is it okay if I email you a soft copy of the right one when I get home?

Professor: What happened to you these days? You need to be more detail-oriented in the future. Well, it's okay. Bring me the right paper tomorrow.

When facing the apologizer with lower social status, the apology receiver, that is, the professor in Scenario 3 , first uses the strategies of "asking for reasons" ("What happened to you these days?") and "cautions" ("You need to be more detail-oriented in the future"), which are "Indirect Refusal" at the macro-level , and then turns to more positive strategies-"formulaic responses" of Direct Acceptance ("it's okay") and "providing solutions" of Indirect Acceptance ("Bring me the right paper tomorrow").

Similarly, for CNSs, the change of social status also affects the AR pattern. When the social status of the apologizers is higher than that of the apology respondents, the latter use the Indirect Acceptance strategy most frequently (56.25\%), among which "minimizations" and "expressing concerns" are the most preferred micro-level strategies. And when facing the apologizers of lower social status, the apology respondents take a balance between the two macro-level strategies of Indirect Acceptance (40.91\%) and Indirect Refusal (36.36\%). For example:

(4) 教授: 不好意思啊, 我迟到了, 有点儿堵车。

Jiaoshou: Buhao yisi a, wo chidao le, you dian'er duche.

Professor: Sorry I'm late. The traffic was a little bit bad.

学生: 没关系, 就几分钟而已嘛。现在是早高峰, 您路上辛苦了!

Xuesheng: Mei guanxi, jiu ji fenzhong eryi ma. Xianzai shi zao gaofeng, nin lushang xinku le!

Student: It doesn't matter. Just a few minutes. The traffic was quite busy in the morning. You must be tired!

(5) 学生: 教授, 真不好意思! 我拿错论文了, 我能明天交给您吗?

Xuesheng: Jiaoshou, zhen buhao yisi! Wo na cuo lunwen le, wo neng mingtian jiao gei nin ma?

Student: Professor, I'm really sorry! I've brought the wrong paper. Can I turn in the right one tomorrow?

教授: 以后做事得仔细点啊! 好吧, 明天带来放我信箱吧。

Jiaoshou: Yihou zuoshi dei zixi dian a! Hao ba, mingtian dailai fang wo xinxiang ba.

Professor: You need to be more careful next time! All right, you can turn it in tomorrow. Please put it into my mail-box.

In example (4), the student use polite strategies by using "downgrading" ("It doesn't matter"), "minimizations" ("Just a few minutes") and "expressing concerns" ("You must be tired") to save the professor's positive face. In example (5), the apology respondent-the professor-uses first the strategy of "cautions" "You need to be more careful next time"), which is an Indirect Refusal AR strategy, and then the strategy of "providing solutions" ("Please put it into my mail-box"), which is under the category of Indirect Acceptance. In this way, the apology respondent displays his identity of being a professor with higher social power than the apologizer.

As for Chinese EFL learners, their AR pattern is different from those of ENSs and CNSs. It seems that the difference in social power between interlocutors does not act much when responding to apologies. Figure 2 shows that the general patterns in both Scenario 1 and Scenario 3 are quite similar, that is, the strategy of Indirect Acceptance is far more preferred than the other strategies by apology respondents in this group. An interesting detail is that when facing the apologizers with lower social status, the apology respondents use Indirect Acceptance strategy $(56.67 \%)$ much more frequently than the strategy of Indirect Refusal $(26.66 \%)$. This is quite different from the patterns used by the participants in the first two groups. It indicates that Chinese learners of English pay less attention to the social status between interlocutors than ENSs and CNSs do. This is perhaps 
because Chinese EFL learners haven't acquired proficient language skills and sufficient sociolinguistic competence in responding to apologies. When they speak in English, they are concerned more about the correct ways of expressing themselves in English than about the social status between speakers, thus, the most frequent use of Indirect Acceptance strategy in both scenarios.

\subsection{The Effect of Social Distance on AR Strategies}

Data also reveal the effects of social distance on the strategies of responding to apologies used by the three groups. For the convenience of comparison, Scenario 5 and Scenario 7 are chosen. In the two scenarios, the social power between interlocutors and the severity of offence are controlled, while the only difference lies in the social distance between the speakers. In Scenario 5, the two speakers are boyfriend and girlfriend, whose social distance is very close; in Scenario 7, the two interlocutors, a boy and a girl, do not know each other, so the social distance between them is relatively great. The results of the influence of social distance on AR strategies used by the three groups of participants are shown in Table 6 and Figure 3.

Table 6. The effect of social distance on AR strategies used by three groups

\begin{tabular}{|c|c|c|c|c|c|c|c|c|c|c|c|c|}
\hline \multirow{3}{*}{$\begin{array}{l}\text { Macro-level } \\
\text { AR strategies } \\
\text { DA }\end{array}$} & \multicolumn{4}{|c|}{ ENS } & \multicolumn{4}{|c|}{ CNS } & \multicolumn{4}{|c|}{ EFL } \\
\hline & \multicolumn{2}{|c|}{ S 5 (-D) } & \multicolumn{2}{|c|}{$\mathrm{S} 7(+\mathrm{D})$} & \multicolumn{2}{|c|}{ S 5 (-D) } & \multicolumn{2}{|c|}{ S $7(+D)$} & \multicolumn{2}{|c|}{ S 5 (-D) } & \multicolumn{2}{|c|}{ S $7(+D)$} \\
\hline & 3 & $11.54 \%$ & 8 & $22.22 \%$ & 2 & $9.09 \%$ & 8 & $53.33 \%$ & 5 & $17.86 \%$ & 7 & $41.18 \%$ \\
\hline IA & 5 & $19.23 \%$ & 24 & $66.67 \%$ & 9 & $40.91 \%$ & 3 & $20.00 \%$ & 12 & $42.86 \%$ & 4 & $23.53 \%$ \\
\hline DR & 0 & 0 & 0 & 0 & 0 & 0 & 0 & 0 & 0 & 0 & 0 & 0 \\
\hline IR & 18 & $69.23 \%$ & 4 & $11.11 \%$ & 11 & $50.00 \%$ & 4 & $26.67 \%$ & 11 & $39.28 \%$ & 6 & $35.29 \%$ \\
\hline Total & 26 & $100 \%$ & 36 & $100 \%$ & 22 & $100 \%$ & 15 & $100 \%$ & 28 & $100 \%$ & 17 & $100 \%$ \\
\hline
\end{tabular}
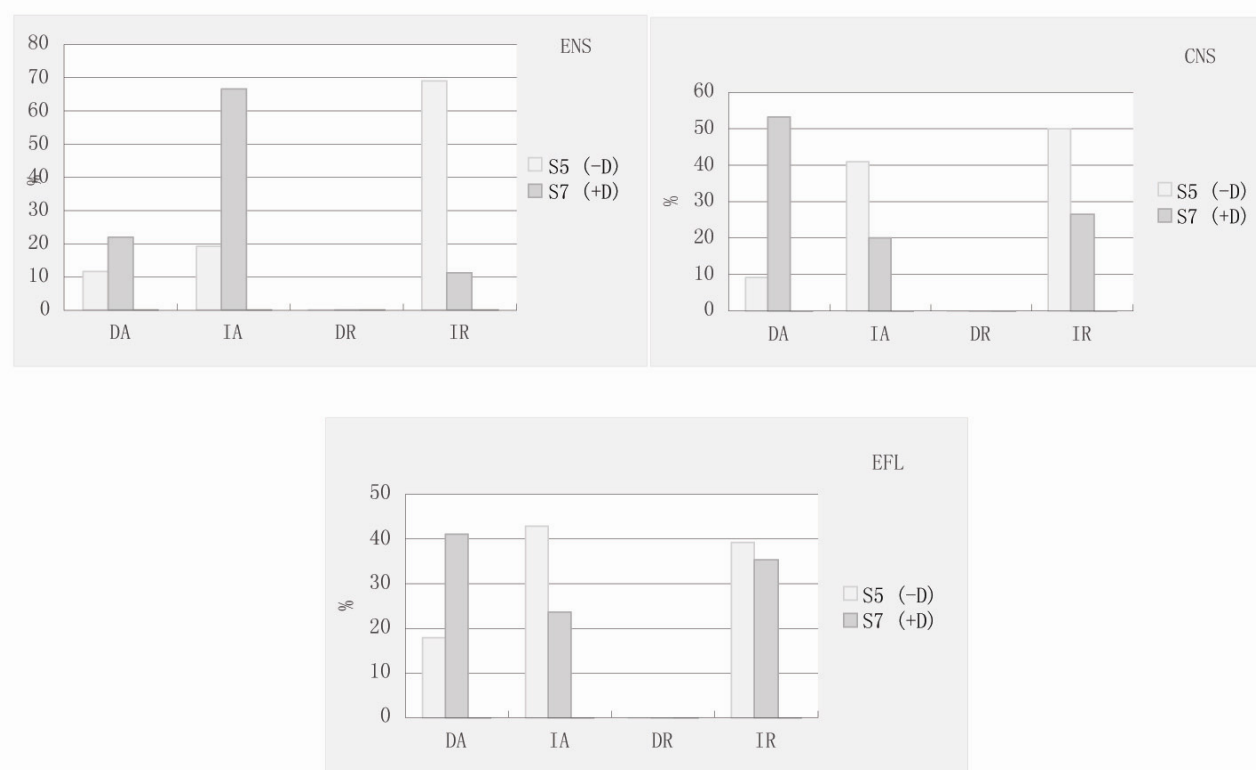

Figure 3. The effect of social distance on AR strategies used by three groups

From Table 6 and Figure 3, it could be learned that when taking into consideration the social distance between interlocutors, ENSs and CNSs display different patterns dealing with AR strategies, and the Chinese EFL learners' AR pattern is somewhat similar to that of CNSs. Specifically, when the speakers are intimate in relationship, ENSs tend to use the macro-level strategy of Indirect Refusal $(69.23 \%)$ far more frequently than Direct Acceptance (11.54\%) and Indirect Acceptance (19.23\%). However, when the interlocutors are detached in relationship, there is an apparent increase in the use of Indirect Acceptance strategy (66.67\%) as well as a deep dive in the use of Indirect Refusal strategy (11.11\%). This suggests that for ENSs, social distance counts a lot in responding to apologies. When the social distance between the speakers enlarges, their AR strategies gradually shift from refusal to acceptance, indicating the increasing politeness.

As for the participants in CNS Group, social distance also plays an important role in their speech act of 
responding to apologies, but the general pattern is different from that of ENS Group. When the social relationship between the interlocutors is intimate, CNSs favor both the strategies of Indirect Acceptance (40.91\%) and Indirect Refusal (50.00\%), but hardly use the strategy of Direct Acceptance (9.09\%). However, when the speakers are strangers to each other, they use the strategy of Direct Acceptance (53.33\%) most frequently. This suggests that CNSs tend to use more polite strategies when facing strangers, through which they can save the faces of both parties and thus enhancing a harmonious relationship between the speakers.

Chinese EFL learners are influenced by their native culture when considering the effect of social distance between interlocutors. When the speakers have an intimate relationship, they tend to use more indirect strategies in responding to apologies. When the social distance between the speakers becomes larger, they show an apparent preference for the strategy of Direct Acceptance (41.18\%), which indicates that they want to perform politely and keep a relatively good profile in front of strangers.

As for the micro-level strategies, here are some examples.

(6) Boyfriend: I am so sorry I'm late, I got held up.

Girlfriend: Why were you held up for so long?

Boyfriend: Well, it wasn't really that long, but I had to do a last minute thing at work.

Girlfriend: I would have liked a call or text because I started to worry.

(7) Boy: Oh! I'm so sorry! Is your foot all right?

Girl: It's okay, it's not your fault. I'm fine, thank you though.

Boy: The bus is so crowded today.

Girl: Yes, it is more crowded than usual.

(8) 男友: 宝贝对不起! 我迟到了。

Nanyou: Baobei duibuqi! Wo chidao le.

Boyfriend: I'm sorry honey! I'm late.

女友: 你知不知道我等了多久? 二十分钟!

Nvyou: Ni zhi bu zhidao wo deng le duojiu? Ershi fenzhong!

Girlfriend: Do you know how long I've been waiting? Twenty minutes!

男友: 我错了! 这是送给你的花。

Nanyou: Wo cuo le! Zhe shi song gei ni de hua.

Boyfriend: It's my fault! These flowers are for you.

女友: 这花儿还不错。看在花的份上就原凉你吧。晚饭你请客!

Nvyou: Zhe hua'er hai bucuo. Kanzai hua de fenshang jiu yuanliang ni ba. Wanfan ni qingke!

Girlfriend: The flowers are nice. I'll forgive you because of the flowers. The dinner will be your treat!

(9) 男孩: 对不起对不起! 有没有受伤?

Nanhai: Duibuqi duibuqi! You mei you shoushang?

Boy: Sorry, sorry! You hurt?

女孩: 没事没事, 不要紧的。

Nvhai: Meishi meishi, bu yaojin de.

Girl: It's OK, it's OK. It's nothing.

The dialogues in examples (6) and (8) are chosen from Scenario 5, in which the boyfriend apologizes to his girlfriend because he has been late for their date for 20 minutes. The two roles in this situation have an intimate social relationship. In example (6), the English native speaker uses the micro-level strategies of "asking for reasons" ("Why were you held up for so long") and "blaming \& complaining" ("I would have liked a call or text"), both of which belong to the macro-level strategy of Indirect Refusal. In example (8), the Chinese girl first uses the micro-level strategy of "blaming \& complaining" ("Do you know how long I've been waiting?"), which 
is a sub-category in the macro-level strategy of Indirect Refusal, and then she uses the strategies of "accepting remedies" ("The flowers are nice") and "providing solutions" ("The dinner will be your treat"), which are both of Indirect Acceptance.

The social distance between the speakers is great in examples (7) and (9), which are taken from Scenario 7. In this situation, the boy accidentally steps on the girl's foot on a bus and is supposed to apologize to the girl, whom he has never met before. In example (7), the girl, an English native speaker, uses the macro-level strategy of Direct Acceptance ("It's OK") and the micro-level strategies of "downgrading" ("It's not your fault"), "appreciation" ("thank you") and "accepting explanations" ("Yes, it is more crowded than usual"), which are all sub-categories of Indirect Acceptance. As for the participants in ENS Group, among all the micro-level strategies of Indirect Acceptance, "downgrading" and "accepting appreciation" are the most frequently used strategies. However, the participants in CNS Group seem to prefer Direct Acceptance strategies. In example (9), the Chinese girl uses the strategy of Direct Acceptance, that is the micro-level strategy of "intensifiers" ("It's OK, it's OK").

\subsection{The Effects of Severity of Offence on AR Strategies}

The last contextual factor we consider here is the severity of offence. We have chosen Scenario 7 and Scenario 8 to explore the influence of this factor on AR strategies used by the three targeted groups. In the two scenarios, the social power and social distance between interlocutors are well controlled. The social power between the boy and the girl in these two scenarios is equal, and the social distance is great. Both of the two roles are university students, and they have never met each other before. The only difference lies in the degree of severity of offence. In Scenario 7, the boy steps on the girl's foot because the bus stops all of a sudden, which causes a minor harm to the girl; while in Scenario 8, the girl accidentally splashes water over the boy's laptop, leading to its collapse, which causes a serious harm to the boy. The results of the influence of severity of offence on AR strategies used by the three groups of participants are shown in Table 7 and Figure 4.

Table 7. The effect of severity of offence on AR strategies used by three groups

\begin{tabular}{|c|c|c|c|c|c|c|c|c|c|c|c|c|}
\hline \multirow{3}{*}{$\begin{array}{l}\text { Macro-level } \\
\text { AR strategies } \\
\text { DA }\end{array}$} & \multicolumn{4}{|c|}{ ENS } & \multicolumn{4}{|c|}{ CNS } & \multicolumn{4}{|c|}{ EFL } \\
\hline & \multicolumn{2}{|c|}{ S $7(-O)$} & \multicolumn{2}{|c|}{$\mathrm{S} 8(+\mathrm{O})$} & \multicolumn{2}{|c|}{ S $7(-\mathrm{O})$} & \multicolumn{2}{|c|}{ S $8(+\mathrm{O})$} & \multicolumn{2}{|c|}{ S $7(-\mathrm{O})$} & \multicolumn{2}{|c|}{$\mathrm{S} 8(+\mathrm{O})$} \\
\hline & 8 & $22.22 \%$ & 4 & $18.18 \%$ & 8 & $53.33 \%$ & 4 & $16.67 \%$ & 7 & $41.18 \%$ & 3 & $15.00 \%$ \\
\hline IA & 24 & $66.67 \%$ & 10 & $45.46 \%$ & 3 & $20.00 \%$ & 7 & $29.17 \%$ & 4 & $23.53 \%$ & 11 & $55.00 \%$ \\
\hline DR & 0 & 0 & 0 & 0 & 0 & 0 & 1 & $4.16 \%$ & 0 & 0 & 0 & 0 \\
\hline IR & 4 & $11.11 \%$ & 8 & $36.36 \%$ & 4 & $26.67 \%$ & 12 & $50.00 \%$ & 6 & $35.29 \%$ & 6 & $30.00 \%$ \\
\hline Total & 26 & $100 \%$ & 22 & $100 \%$ & 22 & $100 \%$ & 24 & $100 \%$ & 28 & $100 \%$ & 20 & $100 \%$ \\
\hline
\end{tabular}
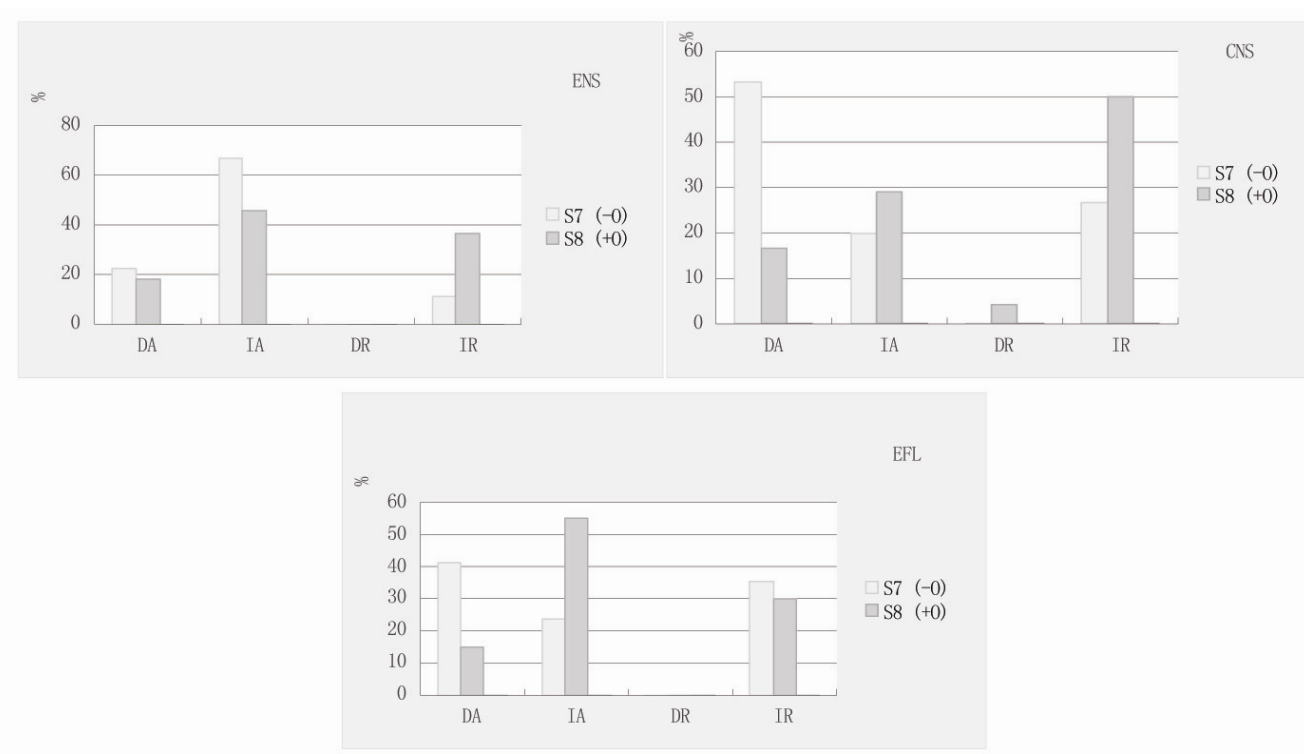

Figure 4. The effect of severity of offence on AR strategies used by three groups 
As for ENS Group, when the offence is not severe, up to $66.67 \%$ of the strategies are Indirect Acceptance, far more than the other three macro-level categories. When the offence becomes severe, though the macro-level strategy of Indirect Acceptance still outnumbers the other three, there is a clear increase in the percentage of Indirect Refusal (from $11.11 \%$ to $36.36 \%$ ) as well as a minor decrease in the use of Direct Acceptance (from $22.22 \%$ to $18.18 \%$ ). This suggests that ENSs do consider the severity of offence when they respond to others' apologies. When the harm they have suffered is slight, they tend to accept others' apologies; when they suffer a greater harm, they will respond to others' apologies by using indirect strategies, including both Indirect Acceptance and Indirect Refusal, to express their annoyance. Here is one example:

(10) Girl: Oh my god, I'm so sorry. Is the computer OK?

Boy: I don't know, it doesn't seem like it's working. You need to be more careful.

Girl: I'm sorry! Let me see if it works after I wipe off the spill ... nope, still doesn't work.

Boy: I need to get it to IT. You're coming with me.

In this example, the boy's computer is broken because of the girl's carelessness. Facing such a loss, the boy first uses the strategies of Indirect Refusal, including "descriptions" ("it doesn't seem like it's working") and "cautions" ("You need to be more careful"), and then the strategy of Indirect Acceptance, namely "providing solutions" ("I need to get it to IT. You're coming with me").

As for CNS Group, there is quite a different pattern of responding to apologies when they face different degrees of offence severity. When the offence is relatively minor, CNSs mostly use the strategy of Direct Acceptance $(53.33 \%)$, and when the offence is severe, they turn to the strategy of Indirect Refusal $(50.00 \%)$. There is an apparent change from acceptance to refusal in the CNSs' pattern of responding to apologies when the degree of offence severity increases. This indicates that for CNSs, the severity of offence is an important factor that they need to consider when responding to others' apologies. When the offence is not so severe, they act very politely in a direct way, and when they suffer greater harm, they will try to respond politely in a more indirect way by using more indirect strategies.

What is interesting and worth mentioning here is that the only response of Direct Refusal from the data emerged in Scenario 8, used by CNSs. Here is the example:

(11) 男孩: 不会吧!

Nanhai: Buhui ba!

Boy: No!

女孩: 啊! 对不起对不起! 我不是故意的!

Nvhai: A! Duibuqi duibuqi! Wo bushi guyi de!

Girl: Ah! Sorry, sorry! I didn't mean to do that!

男孩: 现在道歉来不及了, 电脑都雇了!

Nanhai: Xianzai Daoqiao laibuji le, diannao dou tan le!

Boy: It's no use to apologize now. The computer doesn't work!

女孩: 啊呀, 那怎么办啊? 要不我陪你拿去修修吧?

Nvhai: A ya, na zenmeban a? Yaobu wo pei ni naqu xiuxiu ba?

Girl: Ah, what can I do for you? How about you and I going to the repair store and getting it fixed?

男孩: 只能这样了。真倒霉!

Nanhai: Zhineng zheyang le. Zhen daomei!

Boy: That's the only way. Bad luck!

In this example, when the girl apologizes to the boy, the latter immediately refuses her apology by saying "It's no use to apologize now", which is a strategy of Direct Refusal. When the girl offers a solution to solve the problem, 
the boy accepts it by saying "That's the only way", which is a strategy of "accepting remedies" in the macro-level category of Indirect Acceptance. And finally, by saying "Bad luck", the boy uses the strategy of "blaming and complaining", which is a sub-strategy in the category of Indirect Refusal.

Figure 4 shows that the Chinese EFL learners display an AR pattern different from both the ENSs and the CNSs. The ratios between Acceptance and Refusal in the two scenarios are quite close. In Scenario 7, up to $64.71 \%$ of the strategies belong to the categories of Direct Acceptance and Indirect Acceptance, and $35.29 \%$ of the strategies fall into the categories of Direct Refusal and Indirect Refusal. In Scenario 8, the figures are $70 \%$ and $30 \%$. This indicates that Chinese EFL learners favor acceptance to refusal when they respond to others' apologies in English, a foreign language to them. The severity of offence does not affect them as much as it does to the participants in the first two groups. However, there is quite a remarkable difference in the distribution of Direct Acceptance and Indirect Acceptance. When the offence is not so severe, the participants in Group 3 tend to use more Direct Acceptance strategies (41.18\%) than Indirect Acceptance strategies (23.52\%), and when the offence is severe, they turn to Indirect Acceptance strategies (55.00\%) more often than the strategies of Direct Acceptance (15.00\%). This suggests that in cross-cultural communication, Chinese EFL learners put a lot of emphasis on being polite while to some degree ignoring contextual factors such as the severity of offence.

\section{Conclusion}

\subsection{Summary}

The current study explores the strategies of apology responses used by the native speakers of English and Chinese as well as the Chinese EFL learners. It is found that the three groups display a similar pattern of responding to apologies. Among the four macro-level AR strategies of Direct Acceptance, Indirect Acceptance, Direct Refusal, and Indirect Refusal, Indirect Acceptance is the most preferred response by all the three groups, and is used more frequently by Chinese EFL learners, followed by ENSs and CNSs. Direct Refusal is the least favorable among all the three groups, with only one strategy found in CNSs and none in the other two groups.

With regard to the contextual factors of social power, social distance and severity of offence, we find that the three groups respond to apologies quite differently. Social power plays an important role in responses to apologies of both ENSs and CNSs but not of Chinese EFL learners. When it comes to the social distance between interlocutors, the situation is more complicated. Although the social distance counts a lot in apology responses of all the three groups, ENSs and CNSs display different patterns of dealing with AR strategies, and the Chinese EFL learners' AR pattern is somewhat similar to the pattern of CNSs. Finally, the severity of offence also influences the use of AR strategies of all the three groups. ENSs do consider the severity of offence when they respond to others' apologies; however, this contextual factor affects CNSs and Chinese EFL learners more.

As for Chinese EFL learners, it is found that they are more influenced by their native culture than the target culture when dealing with AR strategies. As the AR strategies in their native culture may differ from those in the target culture, the Chinese EFL learners may have the potential of intercultural pragmatic failure when they communicate with people from western countries. It is in line with the research on the use of apology strategies, as Bataineh \& Bataineh $(2008$, p. 816) point out, "Oftentimes, just that a person is competent in the use of apology strategies in his/her native language does not necessarily mean he/she is as competent in the target language unless, of course, he/she is taught to be so." In this light, to improve Chinese EFL learners' pragmatic competence calls for explicit instructions (House, 1996; Kasper, 2001; Rose \& Kasper, 2001) and more effective pragmatic pedagogy models (Dai \& Yang, 2005).

\subsection{Implication}

The present study contributes some insights into the cross-cultural pragmatics by examining an understudied speech act-responding to apologies-and constructing a framework of apology response strategies within the context of Chinese, an understudied language in intercultural pragmatics. China, ever since ancient times, has been considered as a "nation of rituals". Such face-connected speech acts as apologizing and responding to apologies, as well as the politeness culture reflected by these speech acts, are worth deeply exploring. The current study, thus, may have provided a good chance to look into the Chinese politeness culture from a cross-cultural perspective, thus contributing to the literature on intercultural pragmatics.

Furthermore, the current research is also hoped to have some implications for L2 pragmatic pedagogy in China. In the recent decade, many scholars in China have devoted themselves to the discussion on the teachability and different methods of L2 pragmatic teaching (e.g., Dai \& Yang, 2005; Lu, 2013; Zhao \& Peng, 2013). Although it has been widely accepted that the teaching of L2 pragmatic is important and urgent in China, it is still floating on the surface of theory. Many theory-proved-effective teaching methods have not been put into practice, and as the 
current study finds out, the pragmatic competence of Chinese EFL learners is still not sufficient enough to help them perform smoothly in intercultural communication. Therefore, this study is hoped to raise more attention to the teaching practice of $\mathrm{L} 2$ pragmatic pedagogy in China.

\subsection{Limitation}

Although the current study may help bridge a gap in the research on the speech act of responding to apologies, there are also some limitations. First, the generalizability of the findings may be limited since the participants were just from two universities in a small scale. Second, some scenarios of the role plays could be further improved in concern of participants' real-life experiences. Participants are supposed to play roles that they actually have in real life so that they can produce more realistic conversations. However, in some scenarios, participants were asked to play the role of a professor, which they didn't have any real-life experience. The dialogues they made, therefore, may not reflect the real-life situations (Hudson, et al., 1995). Third, although we have considered some contextual factors of social power, social distance and severity of offence, there are still many other social factors (for example, gender, education level, socioeconomic status, etc.) without being attended to. Finally, we have not adopted the research method of interviews, which may explore further the reasons why the participants respond to others' apologies in that way. Future research can address these limitations with further explorations.

\section{References}

Al-Zumor, A. (2011). Apologies in Arabic and English: An inter-language and cross-cultural study. Journal of King Saud University-Languages and Translation, 23, 19-28. http://dx.doi.org/10.1016/j.jksult.2010.02.001

Bataineh, R. F., \& Bataineh, R. F. (2008). A cross-cultural comparison of apologies by NSs of American English and Jordanian Arabic. Journal of Pragmatics, 40, 792-821. http://dx.doi.org/10.1016/j.pragma.2008.01.003

Beebe, L. M., \& Cummings, M. C. (1996). Natural speech act data versus written questionnaire data: How data collection method affects speech act performance. In S. M. Gass \& N. Joyce (Eds.), Speech acts across cultures: Challenges to communication in a second language (pp. 65-86). Berlin: Mouton de Gruyter.

Bergman, M. L., \& Kasper, G. (1993). Perception and performance in native and nonnative apology. In G. Kasper \& S. Blum-Kulka (Eds.), Interlanguage Pragmatics (pp. 82-107). New York: Oxford University Press.

Blum-Kulka, S. (1982). Learning to say what you mean in a second language: a study of the speech act performance of learners of Hebrew as a second language. Applied Linguistics, 3(1), 29-59. http://dx.doi.org/10.1093/applin/3.1.29

Blum-Kulka, S., House, J., \& Kasper, G. (Eds.). (1989). Cross Cultural Pragmatics: Requests and Apologies. Norwood, NJ: Ablex.

Bodman, J., \& Eisenstein, M. (1988). May God increase your bounty: The expression of gratitude in English by native and non-native speakers. Cross Currents, 15(1), 1-21.

Brown, P., \& Levinson, S. (1987). Politeness: Some Universals in Language Usage. Cambridge: Cambridge University Press.

Chen, X. (2013). Politeness Theory and Foreign Language Studies. Beijing: Foreign Language Teaching and Research Press.

Cheng, D. (2011). New insights on compliment responses: A comparison between native English speakers and

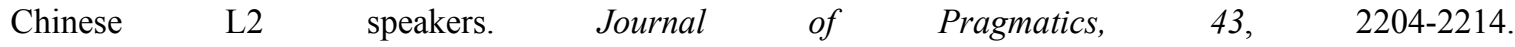
http://dx.doi.org/10.1016/j.pragma.2011.02.003

Coates, J., \& Cameron, D. (1988). Women in their Speech Communities: New Perspectives on Language and Sex. Longman: Harlow.

Cohen, A. D., \& Shively, R. L. (2007). Acquisition of Requests and Apologies in Spanish and French: Impact of Study Abroad and Strategy-Building Intervention. The Modern Language Journal, 91(2), 189-212. http://dx.doi.org/10.1111/j.1540-4781.2007.00540.x

Dai, W., \& Yang, X. (2005). The in-class teaching model of L2 pragmatic acquisition. Foreign Language World, $1,2-8$.

Economidou-Kogetsidis, M. (2012). Modifying oral requests in a foreign language: the case of Greek Cypriot learners of English. In M. Economidou-Kogetsidis \& H. Woodfield (Eds.), Interlanguage Request Modification (pp. 163-202). Amsterdam: John Benjamins. http://dx.doi.org/10.1075/pbns.217.06eco 
Economidou-Kogetsidis, M. (2013). Strategies, modification and perspective in native speakers' requests: A comparison of WDCT and naturally occurring requests. Journal of Pragmatics, 53, 21-38. http://dx.doi.org/10.1016/j.pragma.2013.03.014

Eisenstein, M., \& Bodman, J. (1993). Expressing gratitude in American English. In G. Kasper \& S. Blum-Kulka (Eds.), Interlanguage Pragmatics (pp. 694-781). New York: Oxford University Press.

Felix-Brasdefer, C. (2003). Declining an invitation: a cross-cultural study of pragmatic strategies in Latin American Spanish and American English. Multilingua, 22(3), 225-255. http://dx.doi.org/10.1515/mult.2003.012

Felix-Brasdefer, C. (2007). Pragmatic development in the Spanish as EFL classroom: a cross-sectional study of learner requests. Intercultural Pragmatics, 4(2), 253-286. http://dx.doi.org/10.1515/IP.2007.013

Fraser, B. (1981). On apologizing. In F. Coulmas (Ed.), Conversational Routine: Explorations in Standardized Communication Situations and Prepattenered Speech. Mouton: The Hague. http://dx.doi.org/10.1515/9783110809145.259

Fu, B. (2010). A Discourse Study on the Language of Apologies in Chinese. Language Teaching and Linguistic Studies, 6, 70-77.

Fu, B., Jiang, S., \& Liao, F. (2012). A Study of Strategies for Apologizing and Responding to Apologies between English and Chinese Interlocutors in Discourse. Journal of Zhejiang University of Technology (Social Science), 11(1), 87-92.

Garci'a, C. (1989). Apologizing in English: politeness strategies used by native and non-native speakers. Multilingua, 8, 3-20. http://dx.doi.org/10.1515/mult.1989.8.1.3

Gibney, M., Howard-Hassmann, R. E., Coic aud, J., \& Steiner, N. (2008). The Age of Apology. Philadelphia: University of Pennsylvania Press.

Goffman, E. (1971). Relations in public: Microstudies of the public order. New York: Harper \& Row.

Gu, Y. (1992). Politeness, Pragmatics, and Cultures. Foreign Language Teaching and Research, 4, 10-17/80.

Hartford, B., \& Bardovi-Harlig, K. (1992). Experimental and observational data in the study of interlanguage pragmatics. In L. Bouton \& Y. Kachru (Eds.), Pragmatics and language learning, monograph (vol. 3, pp. 33-50). Urbana-Champaign, IL: DELL.

Hassall, T. (1999). Request strategies in Indonesian. Pragmatics, 9(4), 585-606. http://dx.doi.org/10.1075/prag.9.4.02has

Holmes, J. (1990). Apologies in New Zealand English. Language in Society, 19, 155-199. http://dx.doi.org/10.1017/S0047404500014366

House, J. (1988). "Oh excuse me please ...”: Apologizing in a foreign language. In B. Kettemann, P. Bierbaumer, A. Fill, \& A. Karpf (Eds.), English als Zweitsprache. Tubingen: Narr.

House, J. (1996). Developing pragmatic fluency in English as a foreign language: routines and metapragmatic

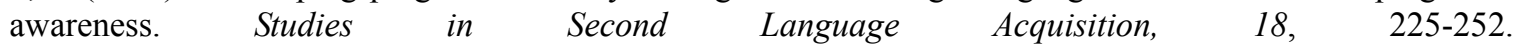
http://dx.doi.org/10.1017/S0272263100014893

Hudson, T., Detmer, E., \& Brown, J. D. (1995). Developing prototypic measures of cross-cultural pragmatics. Honolulu, HI: National Foreign Language Resource Center.

Kasper, G. (2000). Data collection in pragmatics research. In H. Spencer-Oatey (Ed.), Culturally Speaking: Managing Rapport through Talk across Cultures (pp. 316-369). Continuum, London.

Kasper, G. (2001). Classroom research on interlanguage pragmatics. In R. R. Kenneth \& G. Kasper (Eds.), Pragmatics in Language Teaching (pp. 13-32). Cambridge: Cambridge University Press. http://dx.doi.org/10.1017/cbo9781139524797.006

Kasper, G., \& Dahl, M. (1991). Research methods in interlanguage pragmatics. Studies in Second Language Acquisition, 13(2), 215-247. http://dx.doi.org/10.1017/S0272263100009955

Kondo, S. (1997). The development of pragmatic competence by Japanese learners of English: longitudinal study of interlanguage apologies. Sophia Linguistica, 41, 265-284.

Linnell, J. (1992). Can you apologize me? An investigation of speech act performance among non-native speakers of English. Working Papers in Educational Linguistics, 8(2), 33-53. 
$\mathrm{Lu}, \mathrm{J}$. (2013). The influence of classroom pragmatic teaching on the development of Chinese EFL learners' pragmatic development. Journal of PLA University of Foreign Languages, 36(1), 16-19.

Margalef-Boada, T. (1993). Research methods in interlanguage pragmatics: an inquiry into data collection procedures (Doctoral dissertation). Indiana University. Dissertation Abstracts International, 55, 233.

Olshtain, E. (1983). Sociocultural competence and language transfer: the case of apology. In M. Gass \& L. Selinker (Eds.), Language Transfer in Language Learning (pp. 232-249). Rowley, MA: Newbury House.

Olshtain, E., \& Cohen, A. (1983). Apology: a speech act set. In N. E. Wolfson \& E. E. Judd (Eds.), Sociolinguistics and Language Acquisition. Rowly: Newbury House.

Otcu, B., \& Zeyrek, D. (2008).Development of requests: a study of Turkish learners of English. In M. Putz \& J. Neff Van (Eds.), Contrastive Pragmatics: Interlanguage and Cross-cultural Perspectives (pp. 265-300). Berlin/New York: Mouton de Gruyter.

Owen, M. (1983). Apologies and remedial Interchanges: A Study of Language Use in Social Interaction. Berlin, New York, Amsterdam: Mouton Publishers.

Qian, L., \& Yang, H. (2005). A critical analysis of the responses to the speech act of apology in Chinese. Journal of Hefei University of Technology (Social Science), 19(6), 154-156.

Rose, K., \& Kasper, G. (2001). Pragmatics in Language Teaching. Cambridge: Cambridge University Press. http://dx.doi.org/10.1017/cbo9781139524797

Sabate, D. M., \& Curell, G. H. (2007). From "sorry very much" to "I'm ever so sorry:" acquisitional patterns in L2 apologies by Catalan learners of English. Intercultural Pragmatics, 4(2), 287-315.

Shardakova, M. (2005). Intercultural pragmatics in the speech of American L2 learners of Russian: apologies offered by Americans in Russian. Intercultural Pragmatics, 2(4), 423-451. http://dx.doi.org/10.1515/iprg.2005.2.4.423

Sugimoto, N. (1997). A Japan-US comparison of apology styles. Communication Research, 24(4), 349-370. http://dx.doi.org/10.1177/009365097024004002

Trosborg, A. (1987). Apologies strategies in natives/non-natives. Journal of Pragmatics, 11, 147-167. http://dx.doi.org/10.1016/0378-2166(87)90193-7

Turnbull, W. (1997). An appraisal of pragmatic elicitation techniques for the study of talk (Unpublished manuscript). Department of Psychology, Simon Fraser University, Burnaby, BC, Canada.

Wierzbicka, A. (1991). Cross-cultural pragmatics: the semantics of human interaction. Berlin: Mouton de Gruyter.

Woodfield, H. (2012). "I think maybe I want to lend the notes from you": development of request modification in graduate learners. In M. Economidou-Kogetsidis \& H. Woodfield (Eds.), Interlanguage Request Modification (pp. 9-50). Amsterdam: John Benjamins. http://dx.doi.org/10.1075/pbns.217.02woo

Xiang, H. (2004). A Contrastive Study into Apology Strategies: Native British, Chinese graduate students and Chinese EFL learners (Doctoral dissertation). Open University, Melton Keynes, UK.

Yi, Y. (2001). An inquiry into empirical pragmatics data-gathering methods: Written DCTs, oral DCTs, field notes, and natural conversations. Journal of Pragmatics, 33, 271-292. http://dx.doi.org/10.1016/S0378-2166(00)00031-X

Zhao, Y., \& Peng, J. (2013). An empirical study on pragmatic teaching from the perspective of form teaching. Contemporary Foreign Language Studies, 10, 21-23.

\section{Copyrights}

Copyright for this article is retained by the author(s), with first publication rights granted to the journal.

This is an open-access article distributed under the terms and conditions of the Creative Commons Attribution license (http://creativecommons.org/licenses/by/3.0/). 